\title{
Use of Induction Heating in Plastic Injection Molding
}

\author{
Udo Hinzpeter and Elmar Wrona \\ Kunststoff-Institut für die mittelständische \\ Wirtschaft NRW GmbH (K.I.M.W.), Lüdenscheid \\ HÜTTINGER Elektronik GmbH + Co. KG, Freiburg
}

Germany

\section{Introduction}

Variothermal processes are needed in the field of plastic injection molding. They avoid surface faults, enable the modeling of micro structures and the production of micro molded parts. Conventional variothermal processes, which heat with water or oil, have the disadvantage of high cycle times and low productivity. The density of heat flux is very low, and one has to cool down large areas before starting a new injection cycle.

Induction heating enables low cycle times due to excellent heat flux density and the possibility of partial heating. Moreover, induction heating systems save costs. Surface qualities, that are absolutely comparable with varnished parts, are possible with up to 50 times lower cost.

\section{Design of the heating system}

Heat and cool processes become more and more important in the area of injection molding. For economical production it is imperative to use a technology which guarantees high heating and cooling rates. Comparative to all the other possibilities for heat and cool injection molding processes the induction heating of injection molds should be the first election. Figure 1 gives an overview of different induction heating technologies.

This paper shows the technology INDUMOLD®. Some design criteria have to be considered for the design of internal inductors. This is important to reach the required qualitative and economical targets. The major design criteria are:

- $\quad$ sufficient uniform temperature on the mold wall surface

- $\quad$ no increase of the cycle time influenced by the heating and cooling phase

- determination of the generator performance

The arrangement of the inductors is an important step during the design phase of an injection mold since it isn't possible to make a post correction on the existing mold. Because of the complex thermal processes during the injection cycle it is a must to use a suitable simulation program for calculating the temperature distribution (heating and cooling phase). Based on the results of the calculation it is during the mold design phase possible to optimize the inductor arrangement and the cooling channel layout and also to avoid other failure. 


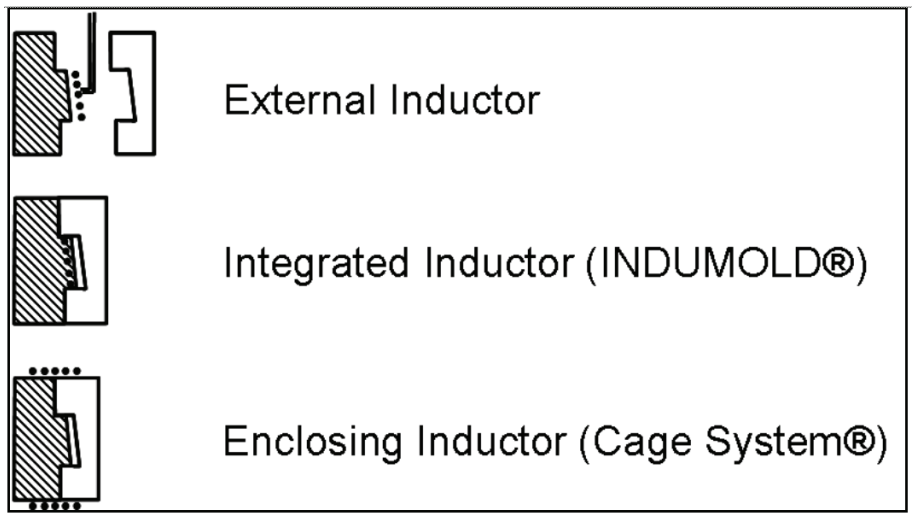

Fig. 1. Overview induction heating techniques for plastic injection molding

The thermal simulation gives information about the reached uniform temperature on the mold wall surface at the end of the heating phase. Furthermore hot and cold spots can be safely detected. Depending on the cooling channel layout it is also feasible to see how the temperature profile during the cooling phase courses and how efficient the mold cooling works. All these results and improvements guarantee that cycle times do not unneeded increase because the design and layout of the inductors and the mold cooling are optimal adjusted of the heat and cool phase.

Figure 2 shows the temperature distribution on the mold wall surface at the end of the heating time. The coloured picture shows the temperature distribution at the end of the heating time. The curves present the temperature course over the time.

It can be identified that the temperature in the middle area is higher as in comparison to the lower handle area. This uneven temperature distribution leads in practice to negative part properties like gloss differences, undue warpage or silver streaks which are shown in Figure 3.

\section{Numerical simulation}

To avoid those failures in practise it is imperative to use convenient simulation software for the induction heating of injection molds. The shown results have been calculated with a simplified thermal simulation program which doesn't consider any electromagnetic effects. This simplification is sufficient for most of the calculations for the induction heating of injection molds based on the INDUMOLD® system.

The software Moldex3D is used for the described calculations which are offered by the Kunststoff-Institut Lüdenscheid. Moldex3D is 3D CAE software for plastic injection molding. The modular structure of the software package makes it possible to adjust it to the individual requirements of the product range of plastic injection molding.

This way it is possible to avoid aberrations in product and mold design before they occur and to realize short developing times at low development costs. It can be used to analyze and optimize any type of complex sprue and cooling geometries. Variothermal and close-tocontour cooling is possible as well as coupled warping for multi-component systems. Based on a 3D hybrid grid and a powerful and robust finite volume algorithm, Moldex3D allows a safe analysis of any type of complex component geometries, multi-component parts with extremely varying wall thicknesses. The scientifically proven models and the extensive 
material data base help to analyze and interpret the processes inside the mold and to tune process parameters. A sufficiently exact analysis of the problems occurring in connection with the injection molding process requires three-dimensional calculation models on the level of the component as well as on the sprue, temperature control and mold level.

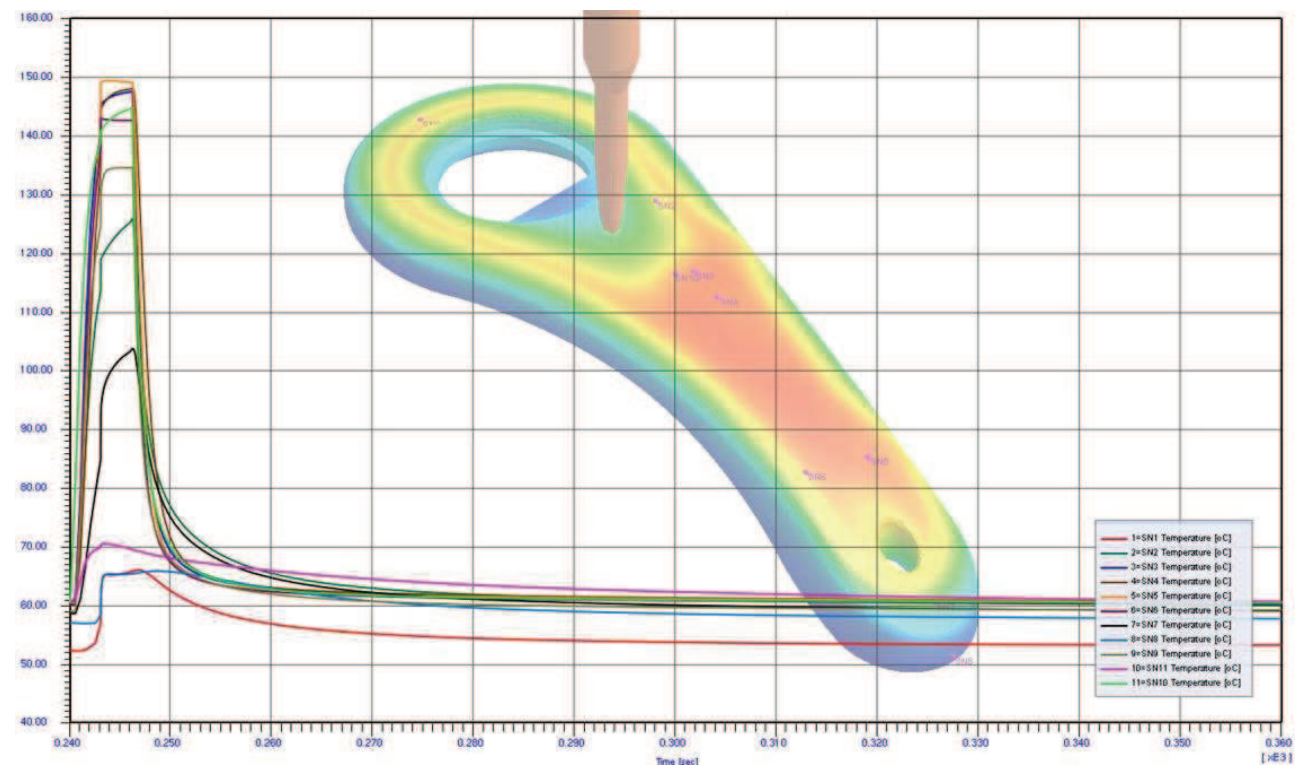

Fig. 2. Temperature distribution on the mold wall surface at the end of the heating time, bottle opener

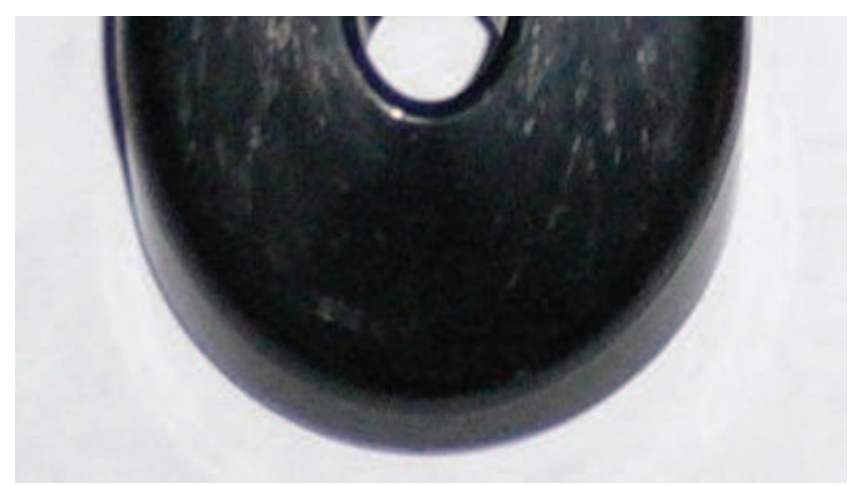

Fig. 3. Warpage and silver streaks at bottle Opener

The needed boundary conditions for a complete simulation of a variothermal injection molding process are:

- part design

- raw material

- $\quad$ processing parameters such as 
- $\quad$ melt and mold wall temperature

- $\quad$ estimated holding pressure and holding pressure time

- injection time

- $\quad$ cycle time

- $\quad$ estimated temperature of the inductor

- $\quad$ heating time

Based on the boundary conditions it is possible to optimize the inductor design and also the whole injection molding process. Depending on the target and the part complexity the duration of the necessary calculations is app. 3-5 days.

A typical CAE service for an injection molding process starts with the generation of a FEM model based on the 3D geometry data. Therefore the general CAD data formats like igs, stl or step can be used. This step could be very labour intensive if the part design is complex or the CAD data quality is bad. If the FEM model is generated the aforementioned boundary conditions have to be assigned. According to the calculation aim a cooling system and also an inductor arrangement have to be added. This could be done by a customer proposal or on a first draft developed by Kunststoff-Institut Lüdenscheid. The first calculation results are evaluated and discussed with the customer for necessary optimization.

\section{Installation concept}

The induction coil consists of a flexible stranded wire, which can be placed very easy in the milled mold. The stranded wire is connected to the external oscillating circuit of the induction heating generator. The generater is controlled by the control system of the plastic injection molding machine via the A/D-interface or Profibus. The control system gives a start signal to the generator. It delivers power for the necessary time by using the internal timer functionality.

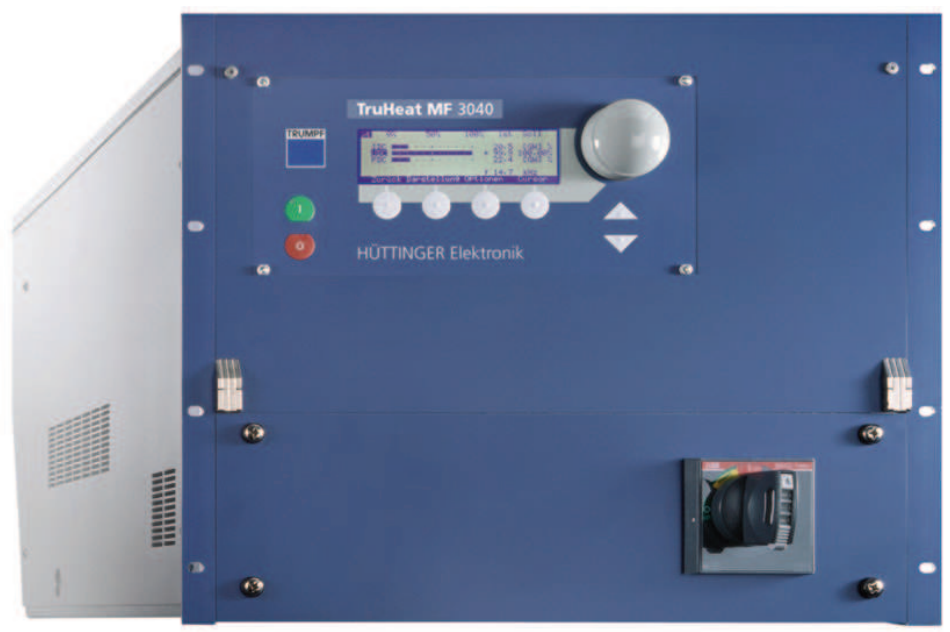

Fig. 4. TruHeat MF 3040, 19-inch plug-in

The required output power depends on the length of the stranded wire and the corresponding mass of the material to be heated. The typical output power is in the range of 
20 to $40 \mathrm{~kW}$. In order to heat only thin layers, frequencies in the range of 70 to $100 \mathrm{kHz}$ are used. If you heat only thin layers, a fast cooling after the injection molding process is possible. Therefore, the cycle times are short.

Typical heating temperatures are between 120 and $180^{\circ} \mathrm{C}$. This temperature range must be realized between 2 and 7 seconds.

\section{Product family TruHeat MF $3010-7040$}

\subsection{General information}

The induction heating is done with the innovative induction heating generator TruHeat MF 3010 - 7040. This product family is available with 10, 20, 30 or $40 \mathrm{~kW}$ output power. The frequency range reaches from 5 to $100 \mathrm{kHz}$. The user has the possibility to operate at any frequency from 5 to $30 \mathrm{kHz}$ or from 20 to $100 \mathrm{kHz}$. The TruHeat MF $3010-7040$ was designed for mains voltages from 400 to $480 \mathrm{~V}$. The generator works at any frequency in this range.

Three different variants of the TruHeat MF 3010 - 7040 are available. The basic version is the 19-inch plug-in module (so called TruHeat MF Series 3000), designed for integration in a 19inch rack (see Figure 4). This very compact unit offers the possibility to integrate the power supply very easy into the facility, e.g. in machines for modern plastic injection molding. This variant already offers the full functionality of the product family. The second version is the tabletop unit (TruHeat MF Series 5000), which is the ideal heating equipment for stand alone operation. This variant is the best choice for laboratories, universities or companies with low amount of space. The third version is the cabinet (TruHeat MF Series 7000). This is the traditional variant for industrial environment with a high protection class IP54. This enables the use even in rough conditions, e.g. in the field of induction hardening.

\subsection{Technical specification}

The 6-puls rectifier is connected directly - without using a relatively space consuming mains transformer - to the mains. This saves space and money.

The DC output voltage of the rectifier is controlled by a chopper unit, which enables to vary the output power (voltage or current) from almost 0 to $100 \%$. Therefore, the TruHeat MF 3010 - 7040 is ideal for high power applications as well as for low power applications, or for processes which need the full power range, e.g. to reach special temperature profiles.

The inverter is operated by an advanced control unit. It recognizes the frequency of the oscillating circuit and chooses the control parameters for the different frequency ranges by itself. As a result, the whole TruHeat MF 3010 - 7040 family needs only one inverter control board.

The output transformer fulfils two functions. It separates the mains potential from the application area and adapts the load to the power supply. The output voltage of the transformer can be switched from 600 to $300 \mathrm{~V}$ or vice versa very easy. Using this feature, the user has the full flexibility to solve different application tasks.

The described components are integrated in the power supply. It is connected with power cables to a parallel oscillating circuit, which has two main advantages in comparison to a serial oscillating circuit. The current in the induction coil - thus the electromagnetic field can be increased by incrementing the factor $\mathrm{Q}$. In addition to that, the matching of the generator and the load can easily be done by changing the capacity. 


\section{Summary}

Induction heating is an innovative technology in the field of plastic injection molding. It enables high quality surfaces at low cycle times and saves costs. To tap the full potential of this technology, numerical simulations are necessary in order to get the best inductor shape. Moreover, the induction heating system and the plastic injection molding facility have to work together perfectly. 


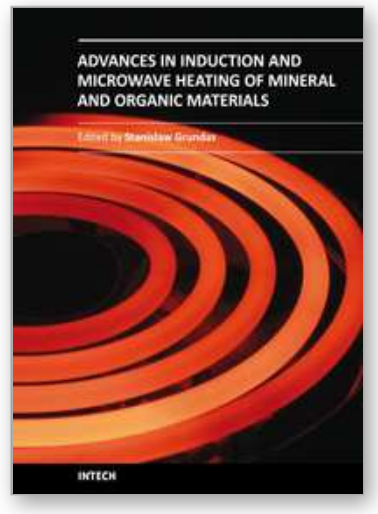

\author{
Advances in Induction and Microwave Heating of Mineral and \\ Organic Materials
}

Edited by Prof. StanisÅ,aw Grundas

ISBN 978-953-307-522-8

Hard cover, 752 pages

Publisher InTech

Published online 14, February, 2011

Published in print edition February, 2011

The book offers comprehensive coverage of the broad range of scientific knowledge in the fields of advances in induction and microwave heating of mineral and organic materials. Beginning with industry application in many areas of practical application to mineral materials and ending with raw materials of agriculture origin the authors, specialists in different scientific area, present their results in the two sections: Section 1-Induction and Microwave Heating of Mineral Materials, and Section 2-Microwave Heating of Organic Materials.

\title{
How to reference
}

In order to correctly reference this scholarly work, feel free to copy and paste the following:

Udo Hinzpeter and Elmar Wrona (2011). Use of Induction Heating in Plastic Injection Molding, Advances in Induction and Microwave Heating of Mineral and Organic Materials, Prof. StanisÅ,aw Grundas (Ed.), ISBN: 978-953-307-522-8, InTech, Available from: http://www.intechopen.com/books/advances-in-induction-andmicrowave-heating-of-mineral-and-organic-materials/use-of-induction-heating-in-plastic-injection-molding

\section{INTECH}

open science | open minds

\section{InTech Europe}

University Campus STeP Ri

Slavka Krautzeka 83/A

51000 Rijeka, Croatia

Phone: +385 (51) 770447

Fax: +385 (51) 686166

www.intechopen.com

\section{InTech China}

Unit 405, Office Block, Hotel Equatorial Shanghai

No.65, Yan An Road (West), Shanghai, 200040, China

中国上海市延安西路65号上海国际贵都大饭店办公楼 405 单元

Phone: +86-21-62489820

Fax: $+86-21-62489821$ 
(C) 2011 The Author(s). Licensee IntechOpen. This chapter is distributed under the terms of the Creative Commons Attribution-NonCommercialShareAlike-3.0 License, which permits use, distribution and reproduction for non-commercial purposes, provided the original is properly cited and derivative works building on this content are distributed under the same license. 